\title{
Interactive comment on "Assimilation of SMOS soil moisture into a distributed hydrological model and impacts on the water cycle variables over the Ouémé catchment in Benin" by $\mathrm{D}$. J. Leroux et al.
}

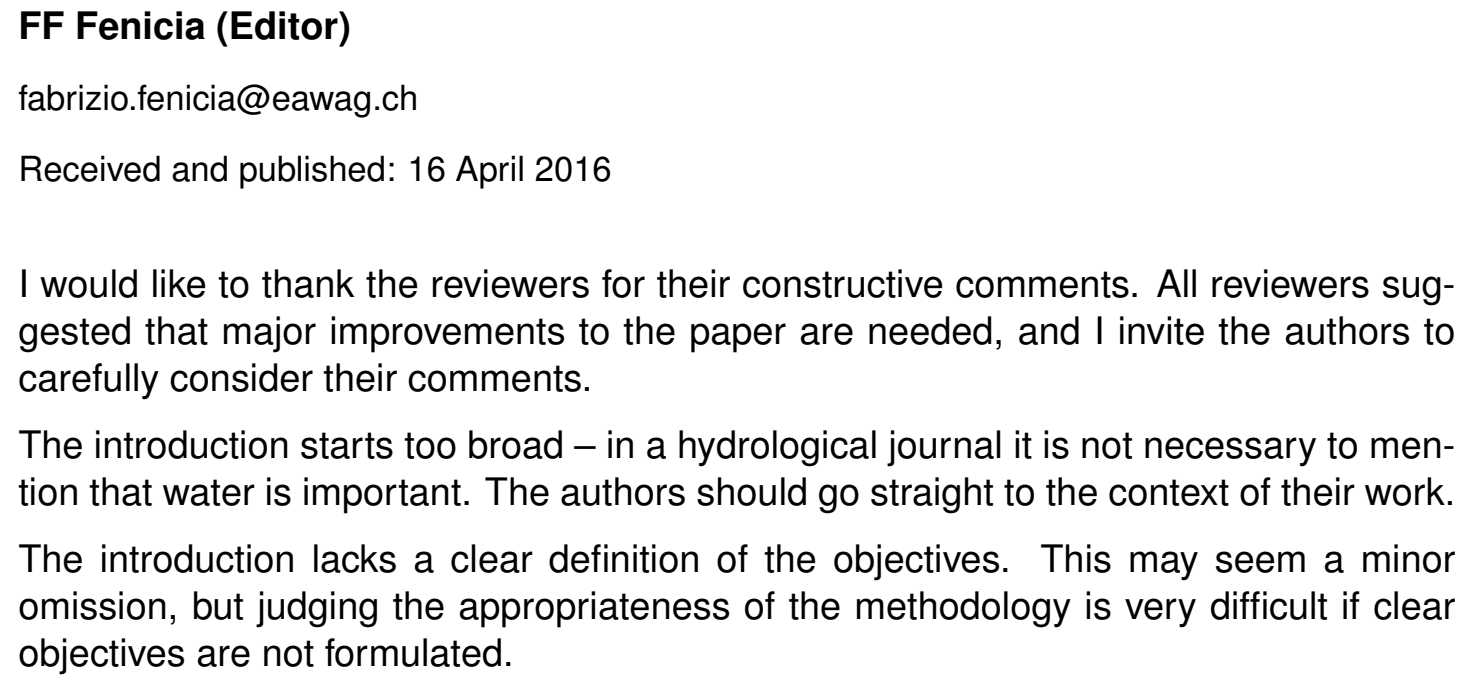

The introduction starts too broad - in a hydrological journal it is not necessary to mention that water is important. The authors should go straight to the context of their work. omission, but judging the appropriateness of the methodology is very difficult if clear objectives are not formulated. 
For example, the authors compare the performance of a model calibrated with a set of input, to the performance of the same calibrated model switching to another set of input. I agree with the point made by Reviewer 2, that in this case the model performance can only deteriorate. The other issue, is that the methodology is applicable only when ground stations are available. The question is why one would want to use satellite data if ground data are present. This question comes back to what are the real objectives of this work.

It seems to me that the states of the ground stations driven model are used as ground truth with respect to the satellite data driven model. I did not find a real justification for this approach, as both models can be wrong.

The hydrological model is called physically based, but then its parameters are calibrated. What is then the definition here used for physically based model? A physically based model is usually defined as one whose parameters should be directly observed.

The authors effectively combine results and discussion. I think these should be clearly separated.

The conclusion is a combination of summary and conclusion. Again, these should be separated.

Interactive comment on Hydrol. Earth Syst. Sci. Discuss., doi:10.5194/hess-2015-548, 2016. 